management. It is reassuring to see that case volumes will probably continue to increase, but training programs will have to adapt to train residents appropriately. Use of simulation labs and comprehensive didactic sessions will be paramount to yield proficient surgeons.

Recently, more attention is being given to milestonebased operative education as a marker of surgical competency. ${ }^{8}$ Trainees learn different skills at varying speeds and comfort levels. While case logs do not accurately depict proficiency, they are a useful metric. As integrated cardiothoracic residencies become more commonplace, we will be training younger, less-developed residents. There will be a wider range of preparation and readiness among trainees. Programs will have to devote more time to maturation processes that previously had occurred during a general surgery residency. Case volume will be just one component in creating a competent cardiothoracic surgeon going forward.

The field of cardiothoracic surgery is changing. With these changes, programs will need to evolve how they train residents. Shah and colleagues have shown that case volume for each trainee is increasing. However, case volume will need to be complemented by many other elements to train proficient surgeons for the future.

\section{References}

1. Lees MC, Zheng B, Daniels LM, White JS. Factors affecting the development of confidence among surgical trainees. J Surg Educ. 2019;76:674-83.

2. Goldsweig AM, Tak HJ, Chen LW, Aronow HD, Shah B, Kolte DS, et al. The evolving management of aortic valve disease: 5 -year trends in SAVR, TAVR and medical therapy. Am J Cardiol. 2019;124:763-71.

3. Stone GW, Lindenfeld J, Abraham WT, Kar S, Lim DS, Mishell JM, et al. Transcatheter mitral-valve repair in patients with heart failure. N Engl J Med. 2019;379:2307-18.

4. Shah A, Siddiqui E, Holmes SD, Okoh A, Abdullah M, Deatrick K, et al. Trends in the traditional cardiothoracic surgery resident operative experience for cardiac cases: an analysis of Accreditation Council for Graduate Medical Education case logs. J Thorac Cardiovasc Surg. 2021;161:1064-75.e3.

5. Mehta H, Osasona A, Shan Y, Goodwin JS, Okereke IC. Trends and outcomes of thoracoscopic lobectomy or segmentectomy: a National Surgical Quality Improvement Project analysis. Semin Thorac Cardiovasc Surg. 2018;30:350-9.

6. Grabski DF, Goudreau BJ, Gillen JR, Kirk S, Novicoff WM, Smith PW, et al. Compliance with the Accreditation Council for Graduate Medical Education duty hours in a general surgery residency program: challenges and solutions in a teaching hospital. Surgery. 2020;167:302-7.

7. Connors RC, Doty JR, Bull DA, May HT, Fullerton DA, Robbins RC. Effect of work-hour restriction on operative experience in cardiothoracic surgical residency training. J Thorac Cardiovasc Surg. 2009;137:710-3.

8. Colbert CY, Dannefer EF, French JC. Clinical competency committees and assessment: changing the conversation in graduate medical education. J Grad Med Educ. 2015;7:162-5.

\title{
Commentary: The kids are alright
}

\author{
Gurion S. Lantz, MD, and Frederick A. Tibayan, MD
}

The growth of percutaneous coronary and valvular interventions, as well as improvements in medical management, are associated with decreases in the number of bread-and-butter cardiac surgeries, such as coronary artery bypass grafting (CABG) and surgical aortic valve replacement (SAVR). ${ }^{1}$

\footnotetext{
From the Division of Cardiothoracic Surgery, Department of Surgery, Oregon Health \& Science University, Portland, Ore.

Disclosures: The authors reported no conflicts of interest.

The Journal policy requires editors and reviewers to disclose conflicts of interest and to decline handling or reviewing manuscripts for which they may have a conflict of interest. The editors and reviewers of this article have no conflicts of interest.

Received for publication Nov 25, 2020; revisions received Nov 25, 2020; accepted for publication Nov 30, 2020; available ahead of print Dec 5, 2020.

Address for reprints: Frederick A. Tibayan, MD, Division of Cardiothoracic Surgery, Department of Surgery, Oregon Health \& Science University, 3181 SW Sam Jackson Park Rd, Mail Code L353, Portland, OR 97239 (E-mail: tibayan@ohsu.edu). J Thorac Cardiovasc Surg 2021;161:1078-9 0022-5223/ $\$ 36.00$

Copyright $\Subset 2020$ Published by Elsevier Inc. on behalf of The American Association for Thoracic Surgery

https://doi.org/10.1016/j.jtcvs.2020.11.147
}

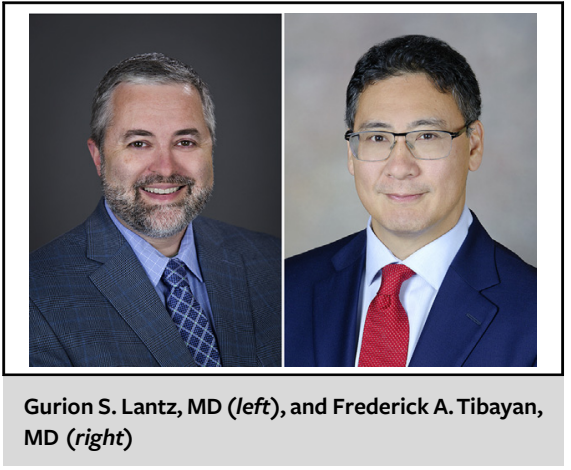

CENTRAL MESSAGE

Despite the changing clinical landscape and decreasing numbers of cardiac surgery cases nationwide, the average resident cardiac surgical volume increased from 2016 to 2019. 
Has this changing landscape had an adverse effect on cardiothoracic surgery (CTS) trainees' surgical volume? In this issue of the Journal, Shah and colleagues ${ }^{2}$ seek to answer this important question by analyzing Accreditation Council for Graduate Medical Education (ACGME) case $\log$ data to identify trends in reported resident case volume between 2016 and 2019.

Assessing the operative exposure of our CTS trainees is eminently sensible. With few exceptions, more operating makes for better operators. Reassuringly, despite the rapidly evolving landscape, much of which favors medical or percutaneous therapies, the authors found that average resident cardiac case volumes increased during the study period. Importantly, this analysis held true not just for total cases, but also for category-specific cases. And although cardiac track residents had greater increases, thoracic track residents also reported larger cardiac case volumes.

There is a clear imperative in CTS training to deliver robust clinical exposure, both in case volume and in direct operative experience. Although the latter is difficult to objectively assess across multiple programs, case numbers are a reasonable surrogate, because these data are captured by the ACGME as a prerequisite for graduation. The accurate recording of cases in these logs has been debated, ${ }^{3}$ and once the minimum cases are captured, there may be little incentive to continue recording cases in a particular category. We encourage all residents to log all their cases beyond the minimums, not only because it helps track program performance, but also because this record of additional experience is "money in the bank" when applying for a job.
Although a perfect study would assess the amount of hands-on operative experience and proficiency of trainees, these data are difficult to capture on a large scale. Many interesting questions related to individual resident data and comparison of integrated, 2-year, and 3-year programs cannot be answered by this otherwise powerful ACGME dataset.

Concerns about surgical case volume are not new. The early days of percutaneous coronary intervention generated concerns about training and predictions of the death of cardiac surgery. But far from dying, the field has remained robust and embraced new technology, as clearly evidenced by the integral role of surgeons in structural heart teams. As we bring this new generation of trainees into the field, they will have to learn new percutaneous skills and achieve proficiency in open surgery. Surgical educators must be up to the challenge to ensure that "the kids are alright."

\section{References}

1. Culler SD, Kugelmass AD, Brown PP, Reynolds MR, Simon AW. Trends in coronary revascularization procedures among Medicare beneficiaries between 2008 and 2012. Circulation. 2015;131:362-70.

2. Shah A, Siddiqui E, Holmes SD, Okoh A, Abdullah M, Deatrick K, et al. Trends in the traditional cardiothoracic surgery resident operative experience for cardiac cases: an analysis of accreditation council for graduate medical education case logs. J Thorac Cardiovasc Surg. 2021;161:1064-75.e3.

3. Robich MR, Flagg A, LaPar DJ, Odell DD, Stein W, Aftab M, et al Understanding why residents may inaccurately log their role in operations: a look at the 2013 in-training examination survey. Ann Thorac Surg. 2016;101: 323-8.

4. The Who. "The Kids Are Alright," My Generation [album]. London: Brunswick Records; 1965. 